Sharif University of Technology
Scientia Iranica
Transactions E: Industrial Engineering
hCIENTIA

\title{
Multi-echelon green open-location-routing problem: A robust-based stochastic optimization approach
}

\author{
R. Vakili ${ }^{\mathrm{a}, *}$, M. Akbarpour Shirazi ${ }^{\mathrm{b}}$, and H. Gitinavard ${ }^{\mathrm{b}}$ \\ a. Department of Economic, Kharazmi University, Tehran, Iran. \\ b. Department of Industrial Engineering and Management Systems, Amirkabir University of Technology, 424 Hafez Ave, Tehran, \\ Iran.
}

Received 2 November 2018; received in revised form 13 March 2019; accepted 18 January 2020

\section{KEYWORDS}

Open-location-routing problem;

Green logistic;

Stochastic

programming;

Robust optimization;

Uncertainty.

\begin{abstract}
In recent years, it has been proven that promoting and observing environmental competence could play an instrumental role in enhancing companies/countries' industries in terms of sustainable development. In this study, a Green Open LocationRouting Problem with Simultaneous Pickup and Delivery (GOLRPSPD) is considered to minimize general costs. In addition to the significance of cost minimization, the objective function aims at promoting environmental competency in terms of the costs of $\mathrm{CO}_{2}$ emissions and fuel consumptions. Meanwhile, in a complex situation, using precise information could yield unreliable results in which considering uncertainty theories could prevent data loss. In this respect, this study assumed the pickup and delivery demand and travel time as probabilistic parameters. To address the issue, a robust stochastic programming approach was developed to reduce the deviations of imprecise information. Moreover, the proposed approach was applied based on five scenarios to decide the best decision in different situations. In addition, a practical example of the multi-echelon openlocation-routing model was provided to represent the feasibility and applicability of the presented robust stochastic programming approach. Finally, comparative and sensitivity analyses were carried out to demonstrate the validity of the proposed approach and, also, to point out the robustness and sensitiveness of the obtained results regarding some significant parameters.
\end{abstract}

(C) 2021 Sharif University of Technology. All rights reserved.

\section{Introduction}

Green location-routing problem covers classic locationrouting with attention to minimizing the cost of fuel consumption and reducing greenhouse gases in the atmosphere, particularly $\mathrm{CO}_{2}$ emitted out by human

\footnotetext{
*. Corresponding author. Tel.: +982126411548 E-mail addresses: avakiliroghaye@gmail.com (R.Vakili); bakbarpour@aut.ac.ir (M. Akbarpour Shirazi); bgitinavard@aut.ac.ir (H. Gitinavard).
}

resource activities. Increasing $\mathrm{CO}_{2}$ causes a critical problem, namely depleting the ozone layer and threatening human health. Thus, organizations and companies are waking up to the necessity of reducing and assessing the environmental effect of operations and services [1]. In this respect, some authors have focused on environmental competencies to solve their location and routing problems.

Thereby, Schneider et al. [2] developed Green Vehicle Routing Problems (GVRP) with time windows to solve green logistics problems in the electric vehicles industry. Erdoğan and Miller-Hooks [3] presented a novel formulation and conceptualization of GVRP 
regarding the proposed density-based clustering and modified Clarke and Wright savings heuristic algorithms. Salimifard and Raeesi [4] developed a new routing problem that accounts for optimization of consumption fuel cost and $\mathrm{CO}_{2}$ emissions by considering a major and cleaner alternative fuel. Tiwari and Chang [5] proposed a block recombination model for the GVRP with the aim of minimizing the distance traveled from depot to distribution center. Montoya et al. [6] presented an extension of the green vehicle routing problem subject to renewable fuel consumption and duration constraints. Dukkanci and Kara [7] extended the classical location-routing problem by considering all of environmental and social side effects of GHG emissions and fuel consumption into the mixed integer programming formulations. According to the importance of environmental issues and presenting an efficient scheme for locating the depots and routing of vehicles, Green Open Location-Routing Problem with Simultaneous Pickup and Delivery (GOLRPSPD) has become a key element of supply chain management.

In many complex GVRP problems, impreciseness inherent in information leads to defining those problems based on uncertain theory. For this purpose, uncertainty theories, such as probabilistic theory, represent powerful tools that can assist managers or experts on the GVRP with overcoming the uncertain environment. Therefore, utilizing the probabilistic theory and their solving tools could be considered as interesting tools for authors to solve the GVRP under imprecise information in practice. Furthermore, assuming probabilistic information using the procedure of extending the multi-echelon open-location-routing could suitably deal with possible uncertain situations in real cases. Meanwhile, a survey of the literature reveals that the authors have focused on multi-echelon location-routing problems based on precise and imprecise information.

In the field of precise information, Hemmelmayr et al. [8] proposed a heuristic solution to the two-echelon vehicle routing problem in two-level transportation systems of city logistics. Contardo et al. [9] introduced a branch-and-cut and an adaptive large-neighborhood search Meta heuristic to solve the two-echelon capacitated location-routing problem. Rahmani et al. [10] presented a mixed integer linear programming formulation for modeling multi-product location-routing with pick-up and delivery in a two-echelon distribution scenario. Redi et al. [11] addressed the open vehicle routing problem with time windows and presented a heuristic algorithm to solve the problem (VSN). Marinakis and Marinaki [12] presented an improved version of the Bumble Bees Mating algorithm for solving the open vehicle routing problem and tested the proposed algorithms by using two sets of benchmark instances. Rahmani et al. [13] presented a mathematical programming model for the two-echelon multi-product location-outing problem with pick-up and delivery.

To solve the problem, two types of local search algorithm are presented. Koç et al. [14] extended the location-routing problem by considering time windows and heterogeneous fleet and presented mixed integer programming formulations and solved the problem using a developed hybrid evolutionary search algorithm. Tajbakhsh and Shamsi [15] extended a bootstrap data envelopment analysis framework with undesirable factors for capacitated facility location problem based on multi-sourcing constraints which are applied to the energy sector of the United States. Chen and Chen [16] presented a model based on the GIS (Geospatial Information System) to obtain the approximate amount of Particular Matter (PM) in the critical part of Tehran.

Capelle et al. [17] modeled the location-routing problem with pickup and delivery using integer programming formulation and validated the model by implementing the column generation. Brandão [18] presented the open vehicle routing problem by considering time concentration and solved the problem using an iterated local search algorithm. Pichka et al. [19] addressed mixed-integer linear programming for the two-echelon open location-routing problem; in this case, for satisfying the open routes, third-party logistics providers were considered. Shen et al. [20] proposed the open vehicle routing problem with time windows that adopted low-carbon trading policies. Wang et al. [21] developed a bi-objective model for two-echelon location-routing problems with time concentration by a three-step customer clustering-based approach. Dai et al. [22] proposed two approaches to multi-echelon location-routing problems and obtained a solution to two location-routing problems within a shorter span of time. Ferreira and Queirez [23] proposed two heuristic algorithms for solving the capacitated location-routing problem. Hosseini et al. [24] addressed the capacitated location-routing problem for a company that collected return products from the customer by designing a collection network. Zhou et al. [25] introduced the two-echelon vehicle routing problem of e-commerce distribution network that happened in the last mile of delivery option. For solving this problem, an effective heuristic algorithm was provided.

In the field of imprecise information, Ghaffari Nasab et al. [26] presented a different stochastic programming model for the capacitated location-routing problem with probabilistic travel times and bi-objective mathematical programming. Zarandi et al. [27] introduced a location-routing problem with time windows which assumed that travel times and demands of customers were fuzzy variables. Bagherinejad and Dehghani [28] proposed a robust optimization of multiobjective capacitated location-allocation model and considered customer demand as an uncertain param- 
eter. Mousavi et al. [29] presented a fuzzy possibilisticstochastic programming model for the location of crossdocking as well as vehicle routing and scheduling. Tajik et al. [30] addressed a new robust model for pollution routing problem with time windows and simultaneous pick-up and delivery by reducing greenhouse emissions and fuel consumption as the objective function. Cheref et al. [31] applied a new robust optimization approach to a production scheduling and delivery routing problem. Schiffer and Walther [32] proposed a robust approach to the location-routing problem for strategic network design of electric supply chain fleet by considering uncertain customer patterns. Shahparvari and Abbasi [33] proposed robust stochastic modeling for the vehicle routing and scheduling problem based on imprecise time windows, evacuee population, and bushfire propagation in Australia.

Wu et al. [34] proposed integer linear scenariobased models under uncertainty by considering travel time as an uncertain parameter and developed a new robust method for the vehicle routing problem. Braaten et al. [35] introduced a robust model of the vehicle routing problem with time windows by considering travel times as uncertainty parameters. Nadizadeh and Kafash [36] addressed the capacitated location-routing with simultaneous pickup and delivery demands in which the pickup and delivery demands of the customer were assumed as fuzzy variables. Lu and Gzara [37] addressed the vehicle routing problem with time windows in the imprecise environment by considering only uncertain demand parameter, presented robust optimization for modeling the problem, and solved the problem with branch and price and cut. $\mathrm{Hu}$ et al. [38] addressed the vehicle routing problem by modeling robust optimization based on new routedependent uncertainty sets, e.g., demand and travel time uncertainty. Veysmoradi et al. [39] offered a mixed integer nonlinear open location-routing model for relief distribution network in the event of a disaster or other uncertain situations such as earthquake and flood.

The investigation of the literature indicates that for the importance of the GOLRPSPD, a robust stochastic model in terms of environmental competencies could deal with imprecise/incomplete information and there are few papers on the robust optimization and stochastic programming approach to the multi-echelon open-location-routing problem, simultaneously. This paper aims to investigate GOLRPSPD problem closer to the real world; therefore, the GOLRPSPD is modeled using stochastic programming and robust optimization in which travel time and customer demands consist of pick-up and delivery demands that are assumed to be probabilistic and it has received insignificant attention in the location-routing problem literature. Following a survey of the literature of location-routing problems, this paper attempts to find possible gaps.

This paper introduced the objective function of estimating GOLRPSPD $\mathrm{CO}_{2}$ emission cost with respect the total system cost in the model considering all the costs associated with $\mathrm{CO}_{2}$ emission in one objective function in order to reduce the amount of fuel consumptions, although it seems to be applicable in real world. Also, given that both pick-up and delivery demands as well as travel time are probabilistic, both probabilistic and robust optimizations as solution methods are applied in the GOLRPSPD. Then, two models are compared to achieve the best result through the use of scenario-based concepts so as to deal with different situations. As shown in Table 1, there is a gap with respect to the robust stochastic approach to solving the open location-routing problem in uncertain situations in terms of environmental concerns. All this consideration in this paper makes mathematical models closer to the real world. However, this paper can be applied to the situations, especially in the distribution management like perishable commodities.

The remainder of this paper is organized as follows: In Section 2, the problem definition and the stochastic and robust mathematical formulations for GOLRPSPD are presented. Besides, a numerical example is considered to represent the implementation

Table 1. Categories of studies on the open location-routing.

\begin{tabular}{|c|c|c|c|c|c|c|c|c|}
\hline Ref. & Location & Routing & Single objective & Open & Green & Deterministic & Stochastic & Robust \\
\hline$[17]$ & $\checkmark$ & $\checkmark$ & $\checkmark$ & & & $\checkmark$ & & \\
\hline [18] & & $\checkmark$ & $\checkmark$ & $\checkmark$ & & $\checkmark$ & & \\
\hline [19] & $\checkmark$ & $\checkmark$ & $\checkmark$ & $\checkmark$ & & $\checkmark$ & & \\
\hline [22] & $\checkmark$ & $\checkmark$ & $\checkmark$ & & & $\checkmark$ & & \\
\hline$[32]$ & $\checkmark$ & $\checkmark$ & $\checkmark$ & & & $\checkmark$ & & $\checkmark$ \\
\hline [37] & & $\checkmark$ & $\checkmark$ & & & $\checkmark$ & & $\checkmark$ \\
\hline$[38]$ & & $\checkmark$ & $\checkmark$ & & & $\checkmark$ & & $\checkmark$ \\
\hline $\begin{array}{l}\text { Current } \\
\text { research }\end{array}$ & $\checkmark$ & $\checkmark$ & $\checkmark$ & $\checkmark$ & $\checkmark$ & $\checkmark$ & $\checkmark$ & $\checkmark$ \\
\hline
\end{tabular}


procedure of the proposed approach in Section 3. Moreover, in Section 4, comparative and sensitivity analyses are carried out to determine the strength of the proposed robust stochastic approach. Finally, some concluding remarks and suggestions for future research are given in Section 5 .

\section{Multi-echelon open-location-routing model}

In this section, the proposed robust stochastic mathematical model for the GOLRPSPD is established. In this respect, the problem description of the multiechelon open-location-routing problem is provided. Then, the assumptions for constructing the proposed model are expressed. Moreover, the stochastic and robust mathematical models for the multi-echelon openlocation-routing problem are developed.

\subsection{Problem definition}

This study focuses on designing the two-echelon openlocation-routing problem including warehouse centers, customers, and recycling centers. In this respect, the objective of this research is to optimize the location of warehouse centers as well as the service routes for delivery of customer demand. These two decisions are optimized by minimizing the total routing costs (e.g., fuel consummation cost) and the warehouse locations costs. In the open-location-routing problem, two customer demands consisting of pick-up and delivery demand are provided in which delivery demand is the demand for products shipped from warehouse centers to customers. Also, each customer has several used and returned products (e.g., empty soda bottles, etc.) which should be shipped to the recycling center by the same vehicle called pick-up demand. Each route starts from a warehouse center and after supplying the customer's delivery demand, the pick-up demands are loaded from customers for shipping to the recycling center. In this respect, output of the recycling center is considered as the materials used in other industries. On the other hand, the recycling center is provided and supplied and, in this respect, the open locationrouting problem occurs when a company does not have its transportation system or when servicing all customers with its fleet is almost impossible because of the absence of the fleet of vehicle. Therefore, these companies usually use the $3 \mathrm{PL}$ company to distribute their commodity due to cost saving and efficient solution. In this respect, this paper considers an open route for transportation system that starts its tour in the depot and does not come back to the depot after servicing the last customer. Meanwhile, the delivery and pick-up demand and the travel time are considered as imprecise parameters.

To address this issue, the robust stochastic programming method is employed with emphasis on the

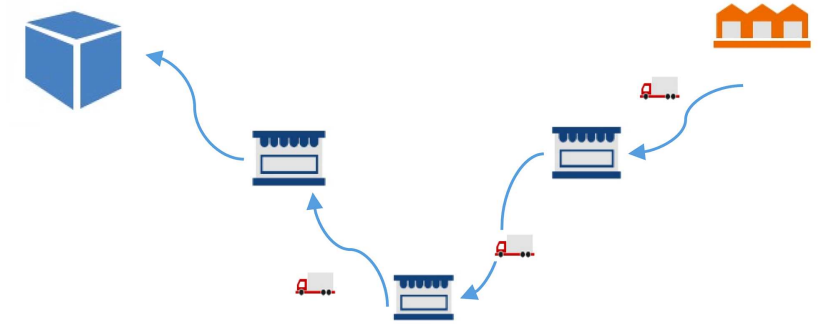

Figure 1. Schematic representation of the open location-routing problem.

scenario-based approach. Indeed, strategic decisions such as establishing a warehouse center are considered in the first stage of the proposed approach and then, tactical decisions such as routing optimization are provided in the second stage according to the scenario-based approach. However, the structure of the GOLRPSPD problem is given in Figure 1.

\subsection{Assumptions}

Some assumptions for extending the multi-echelon open-location-routing model are explained as follows:

- The pick-up and delivery demand and the travel time are uncertain;

- The vehicle routing problem is open in which the output of the recycling center is considered for other industries;

- The supply chain is of two-echelon type that includes warehouses, customers, and a recycling center;

- There is a one-off problem and decisions are taken for a period in the planning horizon;

- The capacity of vehicles is considered different;

- Each customer is serviced by only one warehouse;

- Warehouses have a limited supplying scope;

- Backorder is not allowable;

- In each scenario, some customers may not receive their requested servicing; therefore, the cost of noncovering is considered;

- There is no limitation on travel time;

- The pick-up and delivery are considered, simultaneously;

- Different sequences of future events are considered as possible scenarios.

\subsection{Notations}

In this section, the following notations including sets, parameters, and variables are defined:

Sets

$N=\{1, \cdots, N\}$ Set of all nodes, $N=N_{c} \cup N_{o} \cup N_{r}$ $N_{c}\left(N_{c} \subset N\right) \quad$ Set of customer nodes $\left(j \in N_{c}\right)$ 


\begin{tabular}{|c|c|c|c|}
\hline$N_{o}\left(N_{o} \subset N\right)$ & $\begin{array}{l}\text { Set of possible warehouse center nodes } \\
\left(i \in N_{o}\right)\end{array}$ & $Y_{i j s}$ & $\begin{array}{l}1, \text { if the delivery demand of customer } \\
j \text { is fulfilled by warehouse center } i \text { of } \\
\text { scenario } s \text { otherwise } 0\end{array}$ \\
\hline$N_{r}\left(N_{r} \subset N\right)$ & Set of recycling center nodes & & \\
\hline$K=\{1, \cdots, K\}$ & vehicles & $X_{i j k s}$ & $\begin{array}{l}1 \text {, if vehicle } k \text { goes from node } i \text { to node } \\
j \text { in scenario } s \text {; otherwise, } 0\end{array}$ \\
\hline $\begin{array}{l}E= \\
\{(i, j) \mid i, j \in N\}\end{array}$ & Set of edges & $\operatorname{Cov}_{j s}$ & $\begin{array}{l}1 \text {, if node } j \text { of scenario } s \text { is not fulfilled; } \\
\text { otherwise, } 0\end{array}$ \\
\hline$S=\{1, \cdots, s\}$ & Set of scenarios & $T_{i s}$ & $\begin{array}{l}\text { Vehicle arrival time to node } i \text { in } \\
\text { scenario } s\end{array}$ \\
\hline $\begin{array}{l}\text { Parameters } \\
O_{i} \quad \text { Fixed }\end{array}$ & lis & $S S C_{s}$ & Costs of the second stage related to \\
\hline
\end{tabular}

\subsection{Stochastic mathematical formulation}

One of the most common possibilistic models is the stochastic programming scenario-based approach. As its most important feature, this modeling approach divides decisions into two stages: first, the decisionmaker makes a decision in the first stage and then, a random event may occur in which the secondstage decisions are made to compensate the adverse effects of the first-stage decisions. In this approach, it is not necessary to make decisions in the first and second stages at the same time. Indeed, the secondstage decisions can be postponed until any possible uncertainties are cleared. Moreover, decisions about choosing the best route and transportation fleet can be postponed until one of the considered scenarios occurs. Therefore, problem formulation is presented as a stochastic programming in which imprecise parameters are considered in the form of scenarios in the model. For example, when traffic, vehicle failure, climate change, lack of timely delivery by suppliers, and constant changing of customer's requirements occur, the information on travel time and demand imprecise is affected. These factors represent the source of uncertainty and are considered as the criteria for scenarios. However, the mathematical model of the multi-echelon open-location-routing problem is developed regarding the aforementioned nomenclature as follows:

$$
\begin{aligned}
\min & {\left[\sum_{i \in N_{o}} o_{i} z_{i}+\sum_{s \in S} \operatorname{Pr}_{s} \cdot S S C_{s}\right.} \\
& \left.+\sum_{i \in N_{c}} \operatorname{Pr}_{s} \cdot \operatorname{Cov}_{i s} \cdot\left(d_{i s} \cdot \pi+p_{i s} \cdot \pi^{\prime}\right)\right],
\end{aligned}
$$

where:

$$
\begin{aligned}
S S C_{s}= & \sum_{i \in N_{o}} \sum_{j \in N_{C}} \sum_{k \in K} F_{k} X_{i j k s} \\
& +\sum_{i \in N} \sum_{j \in N} \sum_{k \in K} C_{k} \cdot t_{i j s} \cdot X_{i j k s} \\
& +\sum_{i \in N} \sum_{j \in N} \sum_{k \in K} C_{k}^{\prime} \cdot t_{i j s} \cdot X_{i j k s} \quad \forall s \in S,
\end{aligned}
$$


subject to:

$$
\begin{aligned}
& \sum_{j \in N} \sum_{k \in K} X_{i j k s}+\operatorname{Cov}_{i s}=1 \\
& \forall i \in N_{C}, \quad i \neq j, \quad s \in S, \\
& \sum_{j \in N} X_{i j k s}-\sum_{j \in N} X_{j i k s}=0 \\
& \forall k \in K, \quad i \in N_{C}, \quad s \in S,
\end{aligned}
$$

$\sum_{j \in N} X_{i j k s}=0 \quad \forall k \in K, \quad i \in N_{r}, \quad s \in S$,

$\sum_{k \in K} X_{i j k s} \leq Y_{i j s} \quad \forall i \in N_{o}, \quad j \in N_{c}, \quad s \in S$,

$\sum_{j \in N_{c}} X_{i j k s} \leq b_{k} Z_{i} \quad \forall k \in K, \quad i \in N_{o}, \quad s \in S$

$\sum_{i \in N_{o}} Y_{i j s}+\operatorname{Cov}_{i s}=1 \quad \forall j \in N_{c}, \quad s \in S$,

$\sum_{j \in N_{c}} d_{j s} Y_{i j s} \leq C D_{i} Z_{i} \quad \forall i \in N_{o}, \quad s \in S$,

$U_{j k s}-U_{i k s}+Q_{k} X_{i j k s}+\left(Q_{k}-d_{i s}-d_{j s}\right) X_{j i k s}$

$$
\leq Q_{k}-d_{j s}+\left(1-X_{j i k s}-X_{i j k s}\right) \cdot M
$$

$\forall k \in K, \quad j, i \in N_{c}, \quad j \neq i, \quad s \in S$,

$$
\begin{gathered}
V_{i k s}-V_{j k s}+Q_{k} X_{i j k s}+\left(Q_{k}-p_{i s}-p_{j s}\right) X_{j i k s} \\
\quad \leq Q_{k}-p_{j s}+\left(1-X_{j i k s}-X_{i j k s}\right) \cdot M \\
\forall k \in K, \quad j, i \in N_{c}, \quad j \neq i, \quad s \in S, \\
U_{j k s}+V_{j k s}-d_{j s} \leq Q_{k} \\
\forall j \in N_{c}, \quad k \in K, \quad s \in S,
\end{gathered}
$$

$V_{i k s} \geq p_{i s} \sum_{j \in N, i \neq j} X_{i j k s}+\sum_{j \in N_{c}, i \neq j} p_{j} X_{j i k s}$

$\forall i \in N_{c}, \quad k \in K, \quad s \in S$,

$$
U_{i k s} \geq d_{i s} \sum_{j \in N, i \neq j} X_{i j k s}+\sum_{j \in N_{c}, j \neq i} d_{j s} X_{i j k s}
$$

$\forall i \in N_{c}, \quad k \in K, \quad s \in S$,

$$
U_{i k s} \leq Q_{k}-\left(Q_{k}-d_{i s}\right)\left(\sum_{j \in N_{s}} X_{i j k s}\right)
$$

$$
\forall i \in N_{c}, \quad k \in K, \quad s \in S,
$$

$$
\begin{aligned}
& V_{i k s} \leq Q_{k}-\left(Q_{k}-p_{i s}\right)\left(\sum_{j \in N_{o}} X_{j i k s}\right) \\
& \forall i \in N_{c}, \quad k \in K, \quad s \in S, \\
& T_{i s} \leq \sum_{k \in K} t_{j i s} \cdot X_{j i k s}+T_{j s}+\left(1-\sum_{k \in K} X_{j i k s}\right) \cdot M \\
& \forall i \in N_{c}, \quad j \in N, \quad j \neq i, \quad s \in S, \\
& T_{i s}=0 \quad \forall i \in N_{o}, \quad s \in S, \\
& V_{i k s}, U_{i k s}, T_{i s} \geq 0 \quad \forall i \in N, \quad k \in K, \quad s \in S \\
& Z_{i}, Y_{i j s}, X_{i j k s}, \operatorname{Cov}_{i s} \in\{0,1\} \\
& \forall i, j \in N, \quad k \in K, \quad s \in S .
\end{aligned}
$$

Eq. (1) shows an objective function that minimizes the cost of establishing warehouse centers as well as the expected costs in different scenarios. Thereby, Eq. (2) is established in three parts: routing costs including fixed cost of using vehicles and transportation costs, cost of $\mathrm{CO}_{2}$ emission, and cost of not covering the customer demands, respectively. Constraint (3) guarantees that each customer must be serviced exactly once by vehicle type $k$. Constraint (4) ensures the balance between entering and existing edges of each node.

Constraint (5) ensures that in each scenario, there is no edge exiting from recycling center and all paths end in the recycling center. Constraints (6) and (7) forbid infeasible routes. On the other hand, Constraint (6) ensures that each customer is assigned to a warehouse. Constraint (7) guarantees that if a warehouse is established, only the routes between that warehouse and customers can be activated. Constraint (8) ensures each customer is assigned to exactly a warehouse. Constraint (9) represents the total loading limited to the maximum capacity of the warehouse. Constraint (10) implies that supplying customer demands is related to the warehouse capacity. Constraint (11) ensures that any vehicle that is assigned to a customer can load the pick-up demand. Constraint (12) states that the load of the vehicle must not exceed vehicle capacity. Constraints (12) to (16) define the domain of variables associated with pick-up and delivery products. These constraints along with Constraints (10) and (11) determine the exact value of pick-up and delivery. Constraint (17) expresses the arrival time to customers. Constraint (18) guarantees that arrival time to each warehouse node is zero. Constraints (19) and (20) indicate the positive and binary variables, respectively. 


\subsection{Robust mathematical model}

The robust model carefully examines the planning risk exposure and mitigates the effect of pessimistic state on the results of the system. The robustness ensures that the model results are less sensitive to the variation of scenario parameters, thus facilitating the application of this model in practice and real life. Hence, the robust programming approach developed by $\mathrm{Yu}$ and $\mathrm{Li}$ [40] and Leung et al. [41] is considered in this study. The objective function consists of three terms: The first term shows the costs of the first-stage decisions that are independent of the scenario; the second term minimizes the average costs of the secondstage decisions regarding the scenario-based approach; and the last term estimates variation of uncertain parameters and minimizes deviations from the mean value to ensure robustness. Moreover, the value of coefficients in the last term of the objective function (i.e., coefficient of the average cost $(\lambda)$ and coefficient of deviation from the average cost $(\omega)$ ) depends on experts' opinions. In fact, there is a trade-off between robustness and cost saving. Although robustness of solutions minimizes the variation of uncertainties, while it increases the total cost of the system. The objective function of the robust model is provided as follows:

$$
\begin{aligned}
\min \left[\sum_{i \in N_{o}} o_{i} z_{i}+\sum_{s \in S} \operatorname{Pr}_{s} \cdot S S C_{s}\right. \\
\quad+\lambda \cdot \sum_{s \in S} P r_{s} \cdot\left(\left|S S C_{s}-\sum_{s^{\prime} \in S} P r_{s^{\prime}} \cdot S S C_{s^{\prime}}\right|\right) \\
\left.\quad+\omega \cdot \sum_{i \in N_{c}} \operatorname{Pr}_{s} \cdot \operatorname{Cov}_{i s} \cdot\left(d_{i s} \cdot \pi+p_{i s} \cdot \pi^{\prime}\right)\right]
\end{aligned}
$$

As it was proposed by $\mathrm{Yu}$ and $\mathrm{Li}$ [40], the standard deviation is replaced by average absolute deviation. Furthermore, Eq. (21) should be replaced by Eqs. (22) and (23) to linearize the proposed model in which the considered modifications are represented as follows:

$$
\begin{aligned}
\min \left[\sum_{i \in N_{o}} o_{i} z_{i}+\sum_{s \in S} \operatorname{Pr}_{s} \cdot S S C_{s}\right. \\
\quad+\lambda \cdot \sum_{s \in S} \operatorname{Pr}_{s} \cdot\left(S S C_{s}-\sum_{s^{\prime} \in S} \operatorname{Pr}_{s^{\prime}} \cdot S S C_{s^{\prime}}+2 \theta_{s}\right) \\
\left.\quad+\omega \cdot \sum_{i \in N_{c}} \operatorname{Pr}_{s} \cdot \operatorname{Cov}_{i s} \cdot\left(d_{i s} \cdot \pi+p_{i s} \cdot \pi^{\prime}\right)\right]
\end{aligned}
$$

Subject to:

$$
S S C_{s}-\sum_{s^{\prime} \in S} \operatorname{Pr}_{s^{\prime}} . S S C_{s^{\prime}}+\theta_{s} \geq 0 \quad \forall s \in S .
$$

Constraint (23) states that if $S S C_{s}$ is greater than the mean value, $\theta_{s}$ should be equal to the positive deviation from the mean value of $S S C_{s}$. In contrast, if $S S C_{s}$ is less than the mean value, $\theta_{s}$ should be equal to negative deviation from the mean value of $S S C_{s}$ in Eqs. (24) and (25). Finally, the robust mathematical model is established as follows:

$$
\begin{aligned}
\min & {\left[\sum_{i \in N_{o}} o_{i} z_{i}+\sum_{s \in S} \operatorname{Pr}_{s} \cdot S S C_{s}\right.} \\
& +\lambda \cdot \sum_{s \in S} \operatorname{Pr}_{s} \cdot\left(S S C_{s}-\sum_{s^{\prime} \in S} \operatorname{Pr}_{s^{\prime}} \cdot S S C_{s^{\prime}}+2 \theta_{s}\right) \\
& \left.+\omega \cdot \sum_{i \in N_{c}} \operatorname{Cov}_{i s} \cdot\left(d_{i s} \cdot \pi+p_{i s} \cdot \pi^{\prime}\right)\right]
\end{aligned}
$$

where:

$$
\begin{aligned}
S S C_{s}= & \sum_{i \in N_{o}} \sum_{j \in N_{C}} \sum_{k \in K} F_{k} X_{i j k s} \\
& +\sum_{i \in N} \sum_{j \in N} \sum_{k \in K} C_{k} \cdot t_{i j s} \cdot X_{i j k s} \\
& +\sum_{i \in N} \sum_{j \in N} \sum_{k \in K} C_{i k}^{\prime} \cdot t_{i j s} \cdot X_{i j k s} \quad \forall s \in S .
\end{aligned}
$$

Subject to:

Eqs. (3)-(20).

\section{Experimental example}

In this section, an experimental example is provided to confirm the feasibility and validity of the proposed robust stochastic approach. In this case, assume that there are 15 nodes among which nodes $1-6$ are possible locations for establishing warehouse center, nodes $7-$ 14 belong to customers, and Node 15 is the recycling center. Furthermore, there are 12 vehicles which are divided into three types of vehicles used to move large products and each vehicle is capable of moving one or two pieces with respect to their capacity. The cost of failing to meet a demand is denoted by $\pi^{\prime}=\pi=$ 10 , and also five different scenarios are considered for uncertain parameters. It should be noted that the proposed model can be solved by GAMS CPLEX 10.1 optimization software and the results are obtained using a computer featuring $3 \mathrm{GHz}$ CPU and 4 GB RAM. In this respect, the probability of occurrences is defined as $0.15,0.2,0.3,0.2$, and 0.15 . Moreover, some other parameters such as delivery demand, pick-up demand, and the distance between nodes are represented for instances in Tables 2 to 4, respectively. In the next sections, the results of using the stochastic and robust 
Table 2. The amount of delivery demand for each scenario.

\begin{tabular}{|c|c|c|c|c|c|c|}
\hline \multirow{2}{*}{\multicolumn{2}{|c|}{$\boldsymbol{d}_{j s}$}} & \multicolumn{5}{|c|}{ Scenarios $(S)$} \\
\hline & & 1 & 2 & 3 & 4 & 5 \\
\hline \multirow{8}{*}{ 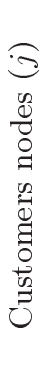 } & 7 & 158 & 221 & 414 & 349 & 699 \\
\hline & 8 & 337 & 411 & 537 & 542 & 1044 \\
\hline & 9 & 236 & 478 & 288 & 276 & 657 \\
\hline & 10 & 324 & 444 & 500 & 545 & 780 \\
\hline & 11 & 278 & 231 & 418 & 605 & 871 \\
\hline & 12 & 246 & 386 & 395 & 356 & 721 \\
\hline & 13 & 207 & 272 & 423 & 384 & 872 \\
\hline & 14 & 196 & 216 & 342 & 457 & 1063 \\
\hline
\end{tabular}

approaches to solving the experimental example are reported. Then, Figures 2 and 3 demonstrate the routes of the solutions to different models and compare them.
Table 3. The amount of pick-up demand for each scenario.

\begin{tabular}{|c|c|c|c|c|c|c|}
\hline & \multicolumn{5}{|c|}{ Scenarios $(S)$} \\
\hline & & 1 & 2 & 3 & 4 & 5 \\
\hline \multirow{8}{*}{ 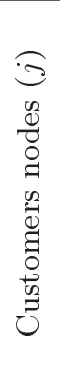 } & 7 & 219 & 340 & 379 & 431 & 279 \\
\hline & 8 & 280 & 199 & 286 & 302 & 275 \\
\hline & 9 & 199 & 333 & 246 & 325 & 458 \\
\hline & 10 & 192 & 231 & 320 & 321 & 422 \\
\hline & 11 & 219 & 285 & 314 & 403 & 400 \\
\hline & 12 & 220 & 218 & 253 & 343 & 289 \\
\hline & 13 & 169 & 213 & 212 & 291 & 378 \\
\hline & 14 & 275 & 308 & 307 & 275 & 409 \\
\hline
\end{tabular}

In Figure 2, the selected fleet of vehicles in the third scenario is shown. As observed earlier, in this scenario, by considering the stochastic parameters, two vehicles of type 2 and two other vehicles of type 3

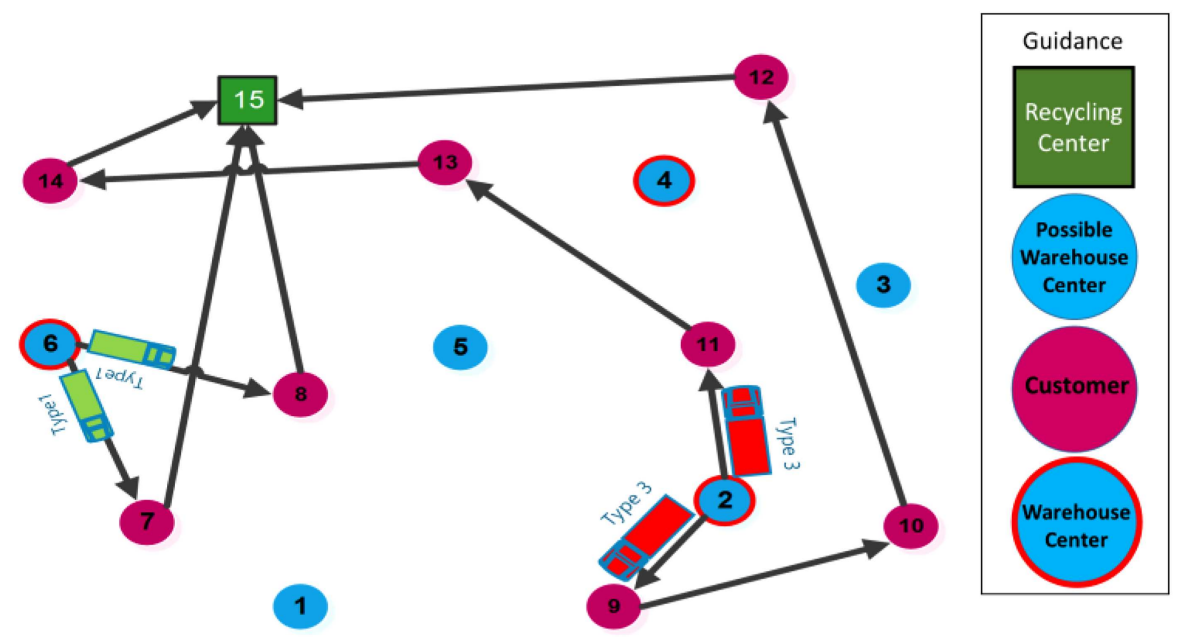

Figure 2. The routes of the solution to the stochastic model for the 3 rd scenario.

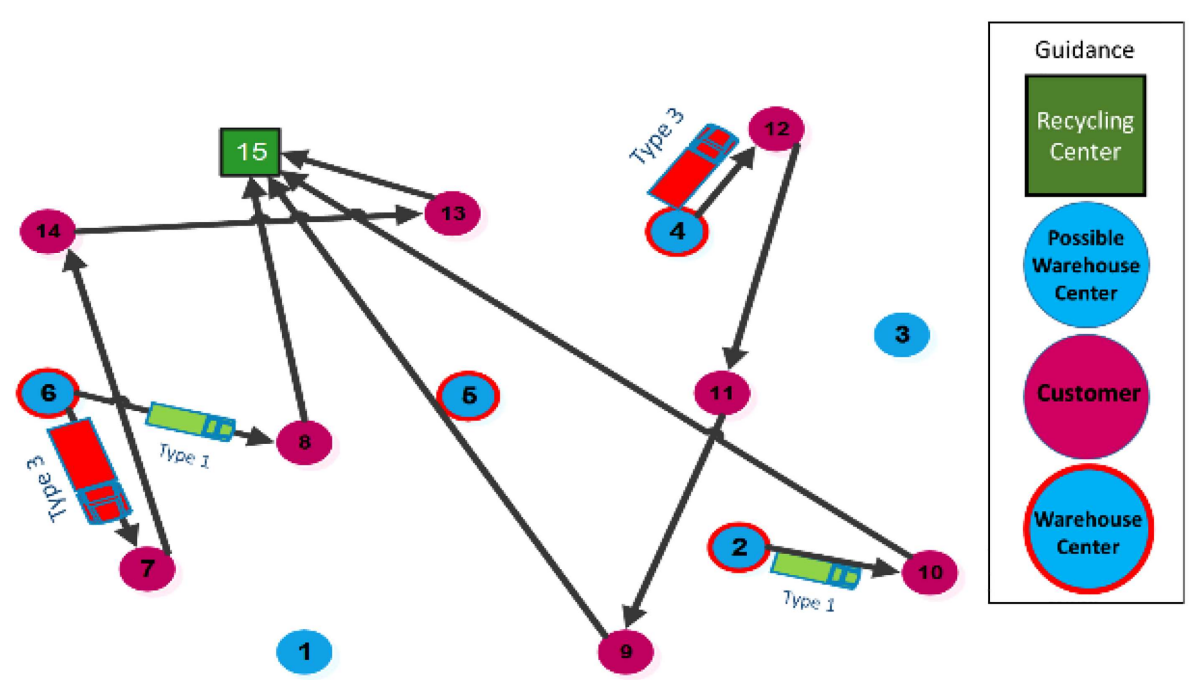

Figure 3. The routes of the solution to the robust model for the 3rd scenario. 
Table 4. Distance between nodes $i$ and $j$.

\begin{tabular}{|c|c|c|c|c|c|c|c|c|c|c|c|c|c|c|c|c|}
\hline \multirow{2}{*}{\multicolumn{2}{|c|}{$d i s_{i j}$}} & \multicolumn{15}{|c|}{ Node $(j)$} \\
\hline & & 1 & 2 & 3 & 4 & 5 & 6 & 7 & 8 & 9 & 10 & 11 & 12 & 13 & 14 & 15 \\
\hline \multirow{15}{*}{$\begin{array}{l}\approx \\
0 \\
0 \\
0 \\
\text { z }\end{array}$} & 1 & 0 & 121 & 190 & 172 & 96 & 110 & 53 & 71 & 86 & 168 & 141 & 215 & 143 & 156 & 167 \\
\hline & 2 & 121 & 0 & 83 & 107 & 87 & 190 & 162 & 121 & 46 & 51 & 52 & 139 & 137 & 211 & 185 \\
\hline & 3 & 190 & 83 & 0 & 69 & 116 & 227 & 219 & 162 & 128 & 79 & 51 & 76 & 135 & 229 & 183 \\
\hline & 4 & 172 & 107 & 69 & 0 & 78 & 176 & 185 & 122 & 141 & 132 & 55 & 42 & 72 & 168 & 117 \\
\hline & 5 & 96 & 87 & 116 & 78 & 0 & 112 & 107 & 46 & 95 & 135 & 68 & 121 & 57 & 125 & 100 \\
\hline & 6 & 110 & 190 & 227 & 176 & 112 & 0 & 63 & 70 & 176 & 241 & 180 & 213 & 110 & 54 & 97 \\
\hline & 7 & 53 & 162 & 219 & 185 & 107 & 63 & 0 & 63 & 134 & 212 & 168 & 226 & 135 & 115 & 143 \\
\hline & 8 & 71 & 121 & 162 & 122 & 46 & 70 & 63 & 0 & 111 & 172 & 113 & 163 & 75 & 97 & 97 \\
\hline & 9 & 86 & 46 & 128 & 141 & 95 & 176 & 134 & 111 & 0 & 85 & 90 & 179 & 152 & 208 & 194 \\
\hline & 10 & 168 & 51 & 79 & 132 & 135 & 241 & 212 & 172 & 85 & 0 & 81 & 152 & 179 & 260 & 228 \\
\hline & 11 & 141 & 52 & 51 & 55 & 68 & 180 & 168 & 113 & 90 & 81 & 0 & 89 & 100 & 187 & 149 \\
\hline & 12 & 215 & 139 & 76 & 42 & 121 & 213 & 226 & 163 & 179 & 152 & 89 & 0 & 104 & 196 & 140 \\
\hline & 13 & 143 & 137 & 135 & 72 & 57 & 110 & 135 & 75 & 152 & 179 & 100 & 104 & 0 & 96 & 50 \\
\hline & 14 & 156 & 211 & 229 & 168 & 125 & 54 & 115 & 97 & 208 & 260 & 187 & 196 & 96 & 0 & 60 \\
\hline & 15 & 167 & 185 & 183 & 117 & 100 & 97 & 143 & 97 & 194 & 228 & 149 & 140 & 50 & 60 & 0 \\
\hline
\end{tabular}

Table 5. The obtained results of the stochastic approach.

\begin{tabular}{lccccc}
\hline$Z^{*}=\mathbf{1 6 7 0 0 . 9}$ & \multicolumn{5}{c}{ Total cost of the first stage=9000 } \\
\hline SSCs (total cost of & $\boldsymbol{S}=\mathbf{1}$ & $\boldsymbol{S}=\mathbf{2}$ & $\boldsymbol{S}=\mathbf{3}$ & $\boldsymbol{S}=\mathbf{4}$ & $\boldsymbol{S}=\mathbf{5}$ \\
the second stage) & 3740.6 & 4305.9 & 4906.1 & 5049.6 & 5432.6 \\
\hline Cost of $\mathrm{CO}_{2}$ emission & 446.9 & 743.1 & 769.0 & 878.4 & 491.4 \\
\hline
\end{tabular}

Table 6. The obtained results of the robust approach.

\begin{tabular}{lccccc}
\hline \multicolumn{1}{c}{$Z^{*}=\mathbf{1 8 0 3 6 . 7}$} & \multicolumn{5}{c}{ Total cost of first stage=12000 } \\
\hline SSCs (total cost of & $\boldsymbol{S}=\mathbf{1}$ & $\boldsymbol{S}=\mathbf{2}$ & $\boldsymbol{S}=\mathbf{3}$ & $\boldsymbol{S}=\mathbf{4}$ & $\boldsymbol{S}=\mathbf{5}$ \\
the second stage) & 3770.2 & 4854.3 & 4997.6 & 5049.6 & 6693.6 \\
\hline Cost of $\mathrm{CO}_{2}$ emission & 758.7 & 966.9 & 798.8 & 878.4 & 569.7 \\
\hline
\end{tabular}

are selected for shipment. Also, it is clear that the establishment of depot number 4 incurs additional cost for the system in the third scenario. As shown in Figure 3, the selected fleet of vehicles in the third scenario consists of two vehicles of type 1 and two other vehicles of type 3 . Moreover, depots numbers 2,4 , and 6 offer services to customers, while the depot number 5 remains inactive. As a result, the selected routes in Figures 2 and 3 completely differ due to the lower costs for the system in each model. In addition, the establishment of depots in two figures is different from each other for the reasons mentioned above.

\subsection{The results of stochastic approach}

In this section, the results of applying the stochastic approach are represented. In this respect, the total value of objective function is 16700.9 and nodes 2, 4, and 6 are considered for establishing the warehouse centers. In this respect, as explained before, the considered approaches are analyzed in two stages. In the first stage, the total cost of establishing warehouse centers is 9000 and in the latter one, the total cost is reported based on the five scenarios given in Table 5. Meanwhile, the fifth scenario has the highest demand, and nodes 7 and 12 for customers are not covered in which the value of objective function increases to 2982. Of note, the total running time for the stochastic approach is 5.52 minutes.

\subsection{The results of robust approach}

In this section, the obtained results of the robust approach application are presented. Meanwhile, the deviation coefficient from average cost $(\lambda)$ and robustness $(\omega)$ is considered to be 2 , simultaneously. In this respect, the value of objective function is 18036.7 and nodes 2, 4, 5, and 6 are allocated to establishing warehouse centers. Furthermore, the costs of establishing the warehouse centers in the first and second stages are reported in Table 6. Moreover, the total 
running time for the robust approach is 45 seconds, which is less than that for the stochastic approach implementation.

\section{Comparative analysis, validation approach, and sensitivity analysis}

\subsection{Comparative analysis}

In this section, the results of the robust model are compared with those of deterministic and stochastic models so that the validity of this approach can be proved. Meanwhile, the proposed approach is employed to determine the value of decision variables for future practice, in which the most suitable decision has the highest value in the objective function. Consequently, the events that are likely to occur in the future are simulated to validate the proposed model and analyze the obtained results. As stated in assumptions, the number of scenarios is considered as different sequences of events that may occur in the future. Consequently, the parameters of each scenario can be accurately determined. Thus, the scenarios with different probabilities are generated for simulating the future and then, input parameters of the deterministic model are considered. The deterministic model determines the cost of making each decision in reality. Indeed, the first-stage variables are constant and equal to those decisions that we desire to make. The deterministic model is presented as follows:

$$
\begin{aligned}
& \min : C_{\text {real }} \cdot X^{*}+C_{\text {real }}^{\prime} \cdot Y+\Pi \cdot R, \\
& A_{\text {real }} \cdot X^{*}+A_{\text {real }}^{\prime} \cdot Y-R \geq B_{\text {real }},
\end{aligned}
$$

where $C_{\text {real }}, C_{\text {real }}^{\prime}, A_{\text {real }}, A_{\text {real }}^{\prime}$, and $B_{\text {real }}$ are defined as the definite values of non-deterministic parameters. Moreover, $X^{*}$ is the constant value of the first-stage variables, and $Y$ is the second-stage variable of the model which is determined when an event occurs. However, the following steps are considered to implement the validation procedure:

Step 1. Solve the deterministic, stochastic, and robust models based on simulation inputs;

Step 2. Store the obtained results of the proposed models as $X_{1}^{*}, X_{2}^{*}, X_{3}^{*}$;

Step 3. Select a scenario randomly and consider its parameters as input data of the deterministic model;
Step 4. Solve the deterministic, stochastic, and robust models for each $X^{*}$ and store the obtained value of objective functions;

Step 5. Repeat Steps 3 and 4 definite times $(N)$;

Step 6. Compute the average, variance, and standard deviation of obtained $N$ values for each objective function of the proposed model.

The implementation process of the validation approach is provided, and the simulation results of deterministic, stochastic, and robust models are reported in Table 7. As represented in this table, the standard deviation of the robust model is significantly less than that of the deterministic and stochastic approaches, which could confirm the validity of the robust model. Furthermore, the average of objective functions indicated that the cost of applying the stochastic model was lower than that of the robust model. Minimization of the imprecise information deviation in the system environment incurs a higher objective function value in the robust model. As mentioned before, while the stochastic model minimizes the average value of costs, the robust model minimizes the deviation from the average value of costs. Therefore, the results show that the average value of costs in the robust model is somewhat higher than that in the stochastic model. In this respect, the trend of the validation approach for deterministic, stochastic, and robust models is given in Figure 4 .

The proposed robust-based stochastic model can appropriately handle uncertain situations in terms of customer demand and travel time as imprecise parameters. However, the relevant methods used in the studies

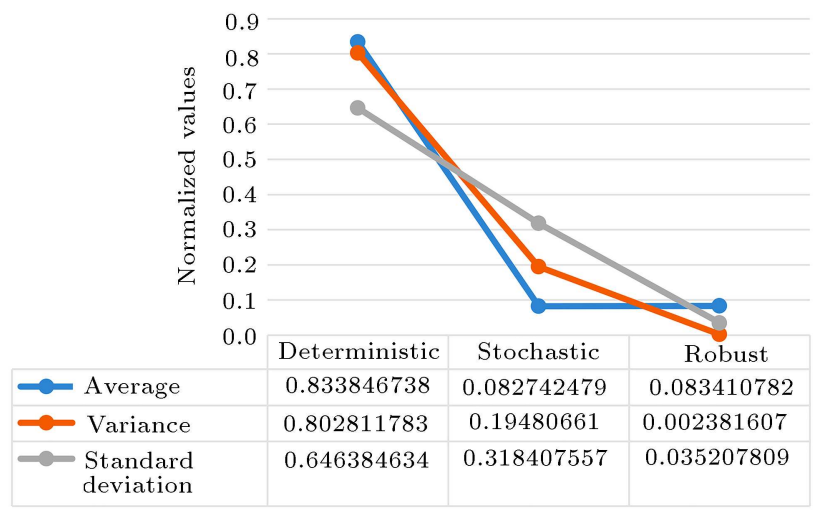

Figure 4. The results of implementation procedure of validation approach for $N=20$.

Table 7. The results of the implementation procedure of the validation approach.

\begin{tabular}{cccc}
\hline $\boldsymbol{N}=\mathbf{2 0}$ & Deterministic model & Stochastic model & Robust model \\
\hline Average & 171185.4 & 16986.7 & 17123.9 \\
Variance & 229131562.7 & 55600009.8 & 679737.5 \\
Standard deviation & 15137.1 & 7456.5 & 824.5 \\
\hline
\end{tabular}


Table 8. Summarized comparative analysis of the proposed approach vs. Lu and Gzara [37] and Hu et al. [38] approaches.

\begin{tabular}{|c|c|}
\hline $\begin{array}{l}\text { Parameters of } \\
\text { the comparison }\end{array}$ & The results of comparisons \\
\hline $\begin{array}{l}\text { Uncertainty } \\
\text { modeling }\end{array}$ & $\begin{array}{l}\text { Because of considering the robust stochastic-based model, the two methods can handle the } \\
\text { vehicle routing problem in uncertain situations, even though only part of the problem faces } \\
\text { uncertainty. However, the proposed approach is tailored in a scenario-based manner to } \\
\text { appropriately elaborate on possible imprecision and achieves the results close to real life by } \\
\text { considering uncertainty under scenarios. }\end{array}$ \\
\hline $\begin{array}{l}\text { Robustness } \\
\text { of model }\end{array}$ & $\begin{array}{l}\text { The proposed approach was employed to determine the robustness of the stochastic } \\
\text { robust-based model by considering such parameters such non-covered customer demand } \\
\text { and feasible routes in comparison to the deterministic model. The results showed the } \\
\text { higher rate of the robustness for the proposed model by analyzing the standard deviation, } \\
\text { which is less than the other three models. However, the methods proposed by Lu and } \\
\text { Gzara [37] and Hu et al. [38] were compared with the deterministic and robust models by } \\
\text { analyzing the feasibility ratio of the robust model and non-covered customer demand, } \\
\text { respectively. Therefore, the greater robustness of the model over those in other studies } \\
\text { cannot be concluded. }\end{array}$ \\
\hline Reliability & $\begin{array}{l}\text { The proposed approach considered the deterministic results and compared those with } \\
\text { stochastic and robust results. Therefore, a chance was presented to reach a promising } \\
\text { and appropriate insight. The studies of Lu and Gzara [37] and Hu et al. [38] did not } \\
\text { consider this concept; therefore, the results of the proposed method in this study were } \\
\text { more reliable. }\end{array}$ \\
\hline Time complexity & $\begin{array}{l}\text { Time complexity is connected to the computational size of the method. Methods of Lu } \\
\text { and Gzara [37] and Hu et al. [38] outperformed the proposed approach. Therefore, } \\
\text { determining the examined factors such as imprecise travel time and demand, time windows, } \\
\text { vehicle capacity, and warehouse capacity and considering these factors through the process } \\
\text { of the proposed scenario-based robust stochastic optimization approach increased the } \\
\text { size of required computation. }\end{array}$ \\
\hline
\end{tabular}

of Lu and Gzara [37] and $\mathrm{Hu}$ et al. [38] are investigated in this study to compare their outcomes. Therefore, the advantages and disadvantages of these approaches and our methods are comparatively listed in Table 8.

\subsection{Validation approach}

In this section, to show the viability of the proposed method and prove its validation in this manuscript, the method suggested by $\mathrm{Lu}$ and Gzara [37] and $\mathrm{Hu}$ et al. [38] is employed to solve the instances in this manuscript. The obtained results are compared and reported in Figure 5. As shown in Figure 5, there is no significant difference between the results of the three compared models.
As evident in Figure 6, the performance of the models is similar to each other. Meanwhile, the standard deviation and variance of the proposed model are lower than those of the robust model vs. the methods of Lu and Gzara [37] and Hu et al. [38]. This finding demonstrates the robustness and reliability of the proposed stochastic model in comparison to the methods of $\mathrm{Lu}$ and Gzara [37] and $\mathrm{Hu}$ et al. [38], proving the validity of the proposed robust model.

\subsection{Sensitivity analysis}

In this section, sensitivity analysis of some parameters is carried out to demonstrate their robustness and sensitiveness in order to ensure the advantages and 
Table 9. The results of variations in the non-coverage coefficient of demand.

\begin{tabular}{lcccccccc}
\hline $\boldsymbol{\omega}$ & $\mathbf{0 . 3}$ & $\mathbf{0 . 6}$ & $\mathbf{0 . 9}$ & $\mathbf{1 . 2}$ & $\mathbf{1 . 5}$ & $\mathbf{1 . 8}$ & $\mathbf{2 . 1}$ & $\mathbf{2 . 4}$ \\
\hline The value of objective function & 13439.7 & 15264 & 17055.2 & 17893.3 & 18036.7 & 18036.7 & 18036.7 & 18036.7 \\
Number of warehouses & 2 & 2 & 3 & 3 & 4 & 4 & 4 & 4 \\
Number of non-covered nodes & 5 & 4 & 2 & 2 & 0 & 0 & 0 & 0 \\
\hline
\end{tabular}

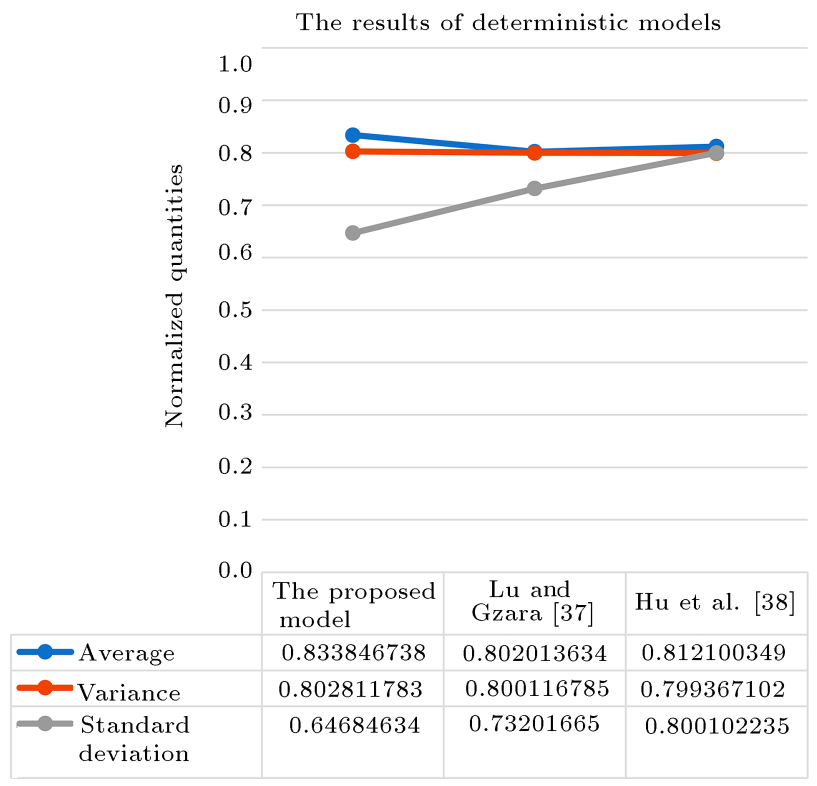

Figure 5. Comparative result of the proposed deterministic model and Lu and Gzara's model [37] and Hu et al.'s model [38].

effectiveness of the proposed approach and to offer a deeper insight. In addition, the performance of the model is also investigated in terms of robustness and based on various key parameters which are critical parameters affecting logistic systems including lead time, customer demand, fixed costs, $\mathrm{CO}_{2}$ emission costs, etc. These parameters are controlled by the important coefficient of the robust model such as noncoverage of customer demand $\omega$ that strongly manages the robustness of the model. In this respect, Table 9 shows sensitivity analysis under variation of $\omega$ which is defined as the coefficient of non-coverage of customer demand in objective function or robustness coefficient. In this analysis, the value of $\omega$ increases to 0.3 in each epoch. As shown in this table, by increasing the cost of non-coverage $(\omega)$, the number of warehouses for serving

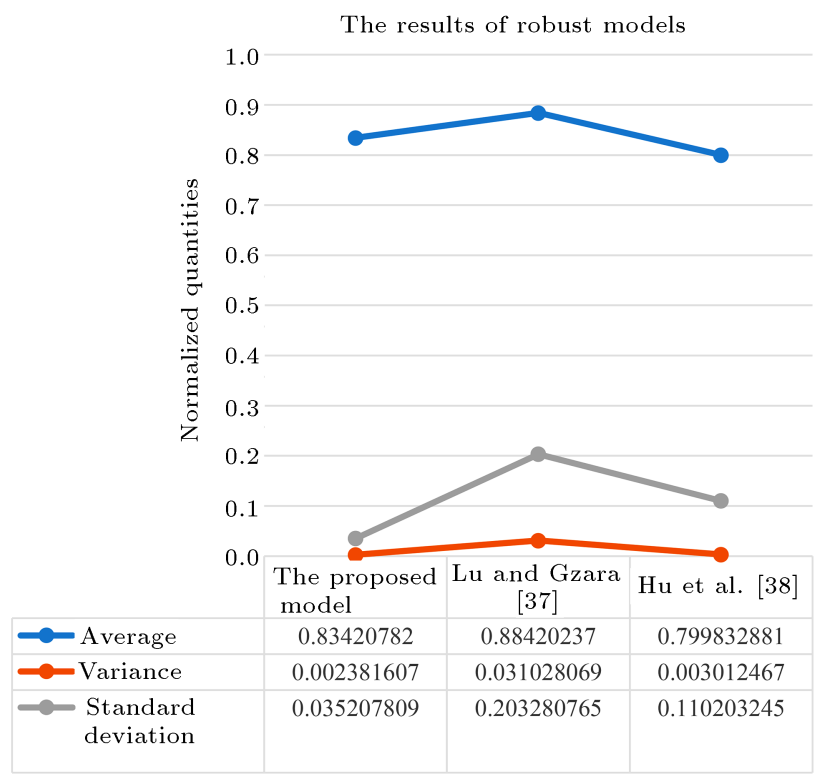

Figure 6. Comparative result of the proposed robust model and Lu and Gzara's model [37] and Hu et al.'s model [38].

the customers increases and, also, the number of noncovered nodes decreases, simultaneously. Furthermore, for $\omega>1.2$, the number of warehouses, non-covered nodes, and the value of objective function are fixed. In addition, a schematic representation of variations of the non-covered demands is given in Figure 7.

Table 5 shows the outcome of sensitivity analysis subject to $\lambda$ variation, which is defined as the optimal robust coefficient. Meanwhile, the value of $\lambda$ increases to 0.5 in each epoch. As reported in Table 10 and depicted in Figure 8, the standard deviation from the mean value of the second-stage costs decreases upon an increase in the value of $\lambda$. In other words, the behavior of the system is more robust by increasing the value of $\lambda$.

Moreover, Table 11 shows the sensitivity anal-

Table 10. The results of optimal stability coefficient variation.

\begin{tabular}{ccccccccc}
\hline $\boldsymbol{\lambda}$ & $\mathbf{0 . 5}$ & $\mathbf{1}$ & $\mathbf{1 . 5}$ & $\mathbf{2}$ & $\mathbf{2 . 5}$ & $\mathbf{3}$ & $\mathbf{3 . 5}$ & $\mathbf{4}$ \\
\hline $\begin{array}{c}\text { The value of } \\
\text { objective function }\end{array}$ & 17230.4 & 17564.0 & 17859.1 & 18036.7 & 18325.0 & 18548.1 & 18700.9 & 18711.4 \\
$\begin{array}{c}\text { Standard deviation of } \\
\text { objective function }\end{array}$ & 1841.0 & 1719.4 & 1281.3 & 1264.5 & 1178.4 & 908.9 & 21.4 & 21.3 \\
\hline
\end{tabular}




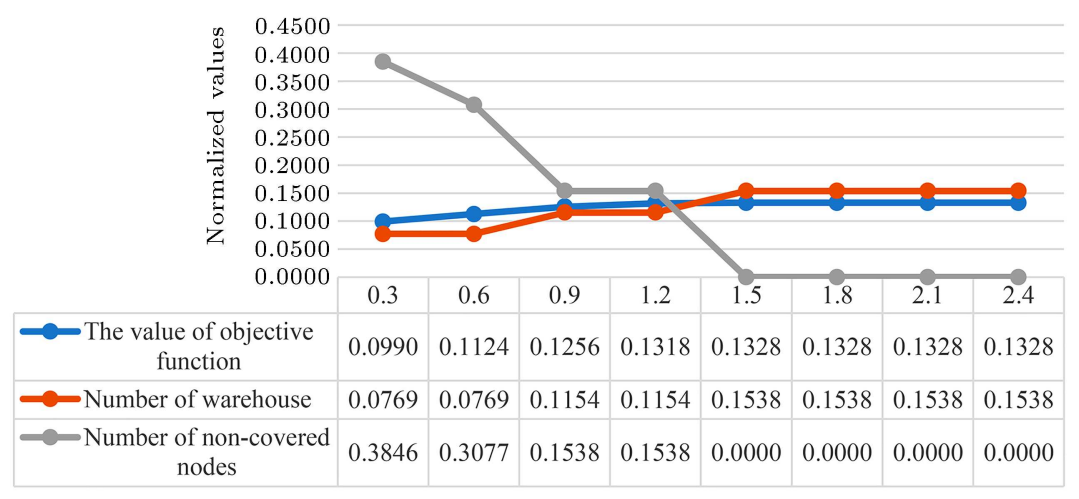

Figure 7. The result of changing the non-covered demands.

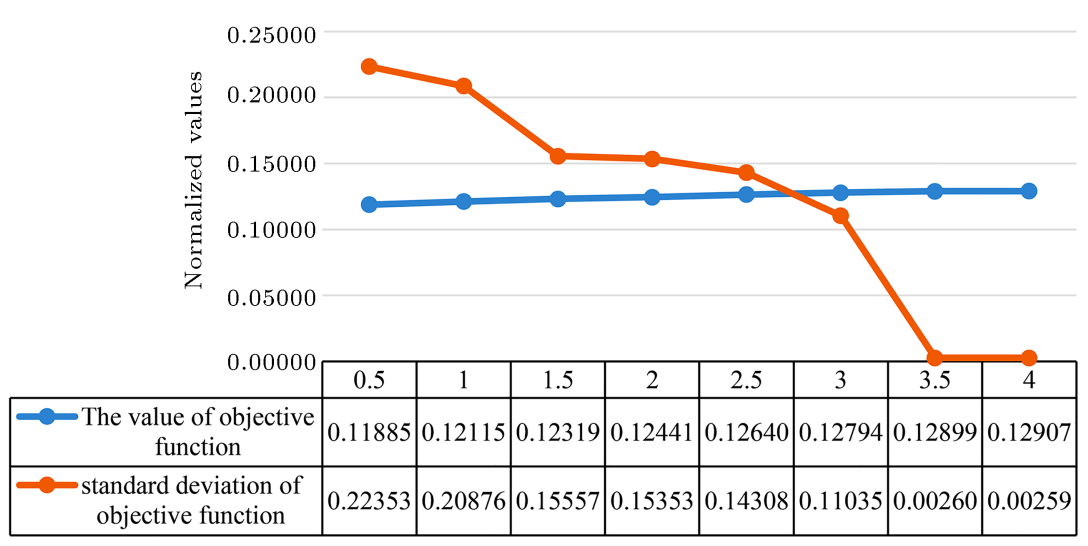

Figure 8. The result of changing the optimal stability coefficient.

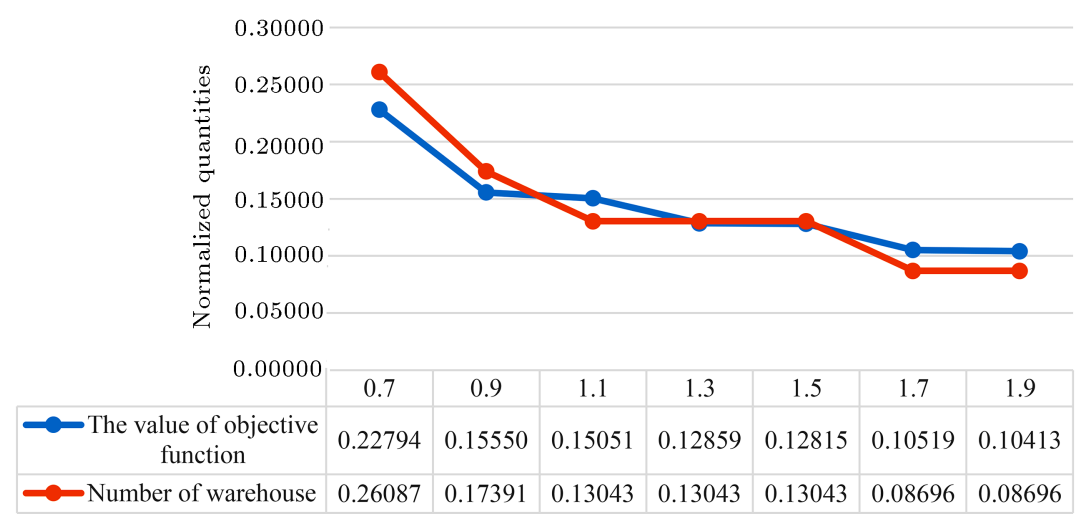

Figure 9. The result of changing the warehouse capacity.

Table 11. The results of warehouse capacity variation $\left(C D_{i}\right)$.

\begin{tabular}{cccccccc}
\hline $\boldsymbol{C D}_{\boldsymbol{i}}$ & $\mathbf{0 . 7}$ & $\mathbf{0 . 9}$ & $\mathbf{1 . 1}$ & $\mathbf{1 . 3}$ & $\mathbf{1 . 5}$ & $\mathbf{1 . 7}$ & $\mathbf{1 . 9}$ \\
\hline The value of objective function & 26851.4 & 18317.4 & 17729.7 & 15147.8 & 15096.6 & 12391.4 & 12266.2 \\
Number of warehouses & 6 & 4 & 3 & 3 & 3 & 2 & 2 \\
\hline
\end{tabular}

ysis under variation of warehouses capacity centers. In this respect, the results show that the number of established warehouses is directly related to the warehouse capacity in which as the warehouse capacity increases, the number of the established ware- houses decreases. Consequently, all warehouse centers are available for customers when the role of warehouse capacity is absent in the decision-making process. Finally, the obtained results are given in Figure 9. 


\section{Conclusions and future directions}

In recent years, companies and countries have increasingly looked upon green logistics due to the significance of environmental competencies in human life. Consequently, logistics strategies should be sustainable and the environmental effects be considered in distribution and production decisions. In this work, two different scenario-based mathematical programming formulations were introduced for the green openlocation-routing problem with stochastic travel time and stochastic pick-up and delivery demand simultaneously, which are called probabilistic programming and robust optimization, respectively. In this respect, the proposed robust stochastic mathematical model was applied to an experimental example to represent the feasibility and applicability of the proposed approach. Hence, the results showed that the first and fifth scenarios of the stochastic and robust models achieved the lowest $\mathrm{CO}_{2}$ emission cost among all the scenarios. However, although the stochastic model achieved lower $\mathrm{CO}_{2}$ emission cost than the robust model, the standard deviation of imprecise variables for the robust model was minimized. Sensitivity analysis was conducted to investigate the performance of the robust model with respect to the variation of some key parameters. The computational results verified the viability of both stochastic and robust models.

Furthermore, a comparative analysis was conducted based on the deterministic, stochastic, and robust models to indicate the efficiency of these methods. Meanwhile, the comparative results based on the values of objective functions showed that a minimum value was reached for the stochastic model. In addition, the robust mathematical model had a lower standard deviation for the obtained results than the two other approaches. However, selecting either stochastic or robust models depends on the experts who are sensitive to either fluctuating results or desiring the minimum cost of $\mathrm{CO}_{2}$ emissions. Due to the difficulties of the problem, the proposed model could only deal with small-sized instances, which is the major limitation of this study and deserves to be addressed in future researches.

By and large, extending the proposed approach based on inventory decisions could yield realistic results. Moreover, metaheuristic solving approaches may be appropriately applied to solve the Green Open Location-Routing Problem with Simultaneous Pickup and Delivery (GOLRPSPD) for large-sized problems. Finally, the proposed approach could be applied to a wide range of problems associated with the distribution management of perishable products.

\section{References}

1. Neto, J.Q.F., Walter, G., Bloemhof, J., Nunen, J.V., and Spengler, T. "A methodology for assessing ecoefficiency in logistics networks", European Journal of Operational Research, 193(3), pp. 670-682 (2009).

2. Schneider, M., Stenger, A., and Goeke, D. "The electric vehicle-routing problem with time windows and recharging stations", Transportation Science, 48(4), pp. 500-520 (2014).

3. Erdoğan, S. and Miller-Hooks, E. "A green vehicle routing problem", Transportation Research Part E: Logistics and Transportation Review, 48(1), pp. 100114 (2012).

4. Salimifard, K. and Raeesi, R. "A green routing problem: optimising $\mathrm{CO}_{2}$ emissions and costs from a bifuel vehicle fleet", International Journal of Advanced Operations Management, 6(1), pp. 27-57 (2014).

5. Tiwari, A. and Chang, P.-C. "A block recombination approach to solve green vehicle routing problem", International Journal of Production Economics, 164, pp. 379-387 (2015).

6. Montoya, A., Gueret, C., Mendoza, J.E., and Villegas, J.G. "A multi-space sampling heuristic for the green vehicle routing problem", Transportation Research Part C: Emerging Technologies, 70, pp. 113-128 (2016).

7. Dukkanci, O. and Kara, B.Y. "Green location routing problem", In European Working Group on Location Analysis Meeting, 5, pp. 32-45 (2015).

8. Hemmelmayr, V.C., Cordeau, J.-F., and Crainic, T.G. "An adaptive large neighborhood search heuristic for two-echelon vehicle routing problems arising in city logistics", Computers \& Operations Research, 39(12), pp. 3215-3228 (2012).

9. Contardo, C., Hemmelmayr, V., and Crainic, T.G. "Lower and upper bounds for the two-echelon capacitated location-routing problem", Computers \& Operations Research, 39(12), pp. 3185-3199 (2012).

10. Rahmani, Y., Oulamara, A., and Cherif, W.R. "Multiproducts location-routing problem with pickup and delivery: Two-Echelon model", IFAC Proceedings Volumes, 46(7), pp. 198-203 (2013).

11. Redi, A.P., Maghfiroh, M.F., and Vincent, F.Y. "An improved variable neighborhood search for the open vehicle routing problem with time windows", Industrial Engineering and Engineering Management (IEEM), 11(1), pp. 87-93 (2013).

12. Marinakis, Y. and Marinaki, M. "A bumble bees mating optimization algorithm for the open vehicle routing problem", Swarm and Evolutionary Computation, 15, pp. 80-94 (2014).

13. Rahmani, Y., Cherif-Khettaf, W.R., and Oulamara, A. "A local search approach for the two-echelon multiproducts location-routing problem with pickup and delivery", IFAC-Papers OnLine, 48(3), pp. 193-199 (2015).

14. Koç, Ç., Betas, T., Jabali, O., and Laporte, G. "The fleet size and mix location-routing problem with time 
windows: Formulations and a heuristic algorithm", European Journal of Operational Research, 248(1), pp. 33-51 (2016).

15. Tajbakhsh, A. and Shamsi, A. "A facility location problem for sustainability-conscious power generation decision makers", Journal of Environmental Management, 230, pp. 319-334 (2019).

16. Chen, J.-X. and Chen, J. "Supply chain carbon footprinting and responsibility allocation under emission regulations", Journal of Environmental Management, 188, pp. 255-267 (2017).

17. Capelle, T., Cortes, C.E., Gendreau, M., Rey, P.A., and Rousseau, L.M. "A column generation approach for location-routing problems with pickup and delivery", European Journal of Operational Research, 272(1), pp. 121-131 (2019).

18. Brandão, J. "Iterated local search algorithm with ejection chains for the open vehicle routing problem with time windows", Computers \& Industrial Engineering, 120, pp. 146-159 (2018).

19. Pichka, K., Bajgiran, A.H., Petering, M.E.H., Jang, J., and Yue, X. "The two echelon open location routing problem: Mathematical model and hybrid heuristic", Computers \& Industrial Engineering, 121, pp. 97-112 (2018).

20. Shen, L., Tao, F., and Wang, S. "Multi-depot open vehicle routing problem with time windows based on carbon trading", International Journal of Environmental Research and Public Health, 15(9), p. 2025 (2018).

21. Wang, Y., Assogba, K., Liu, Y., Ma, X., Xu, M., and Wang, Y. "Two-echelon location-routing optimization with time windows based on customer clustering", Expert Systems with Applications, 104, pp. 244-260 (2018).

22. Dai, Z., Aqlan, F., Gao, K., and Zhou, Y. "A two-phase method for multi-echelon location-routing problems in supply chains", Expert Systems with Applications, 115, pp. 618-634 (2019).

23. Ferreira, K.M. and de Queiroz, T.A. "Two effective simulated annealing algorithms for the locationrouting problem", Applied Soft Computing, 70, pp. 389-422 (2018).

24. Hosseini, M.B., Dehghanian, F., and Salari, M. "Selective capacitated location-routing problem with incentive-dependent returns in designing used products collection network", European Journal of Operational Research, 272(2), pp. 655-673 (2019).

25. Zhou, L., Baldacci, R., Vigo, D., and Wang, X. "A multi-depot two-echelon vehicle routing problem with delivery options arising in the last mile distribution", European Journal of Operational Research, 265(2), pp. 765-778 (2018).
26. Ghaffari-Nasab, N., Jabalameli, M.S., Aryanezhad, M.B., and Makui, A. "Modeling and solving the biobjective capacitated location-routing problem with probabilistic travel times", The International Journal of Advanced Manufacturing Technology, 67(9-12), pp. 2007-2019 (2013).

27. Zarandi, M.H.F., Hemmati, A., Davari, S., and Turksen, I.B. "Capacitated location-routing problem with time windows under uncertainty", Knowledge-Based Systems, 37, pp. 480-489 (2013).

28. Bagherinejad, J. and Dehghani, M. "A multi-objective robust optimization model for location-allocation decisions in two-stage supply chain network and solving it with non-dominated sorting ant colony optimization", Scientia Iranica, 22(6), pp. 2604-2620 (2015).

29. Mousavi, S.M., Vahdani, B., Tavakkoli-Moghaddam, R., and Hashemi, H. "Location of cross-docking centers and vehicle routing scheduling under uncertainty: A fuzzy possibilistic-stochastic programming model", Applied Mathematical Modelling, 38(7-8), pp. 22492264 (2014).

30. Tajik, N., Tavakkoli-Moghaddam, R., Vahdani, B., and Mousavi, S.M. "A robust optimization approach for pollution routing problem with pickup and delivery under uncertainty", Journal of Manufacturing Systems, 33(2), pp. 277-286 (2014).

31. Cheref, A., Artigues, C., and Billaut, J.-C. "A new robust approach for a production scheduling and delivery routing problem", IFAC-Papers OnLine, 49(12), pp. 886-891 (2016).

32. Schiffer, M. and Walther, G. "Strategic planning of electric logistics fleet networks: A robust locationrouting approach", Omega, 80, pp. 31-42 (2018).

33. Shahparvari, S. and Abbasi, B. "Robust stochastic vehicle routing and scheduling for bushfire emergency evacuation: An Australian case study", Transportation Research Part A: Policy and Practice, 104, pp. 32-49 (2017).

34. Wu, L., Hifi, M., and Bederina, H. "A new robust criterion for the vehicle routing problem with uncertain travel time", Computers \& Industrial Engineering, 112, pp. 607-615 (2017).

35. Braaten, S., Gjonnes, O., Hvattum, L.M. and Tirado, G. "Heuristics for the robust vehicle routing problem with time windows", Expert Systems with Applications, 77, pp. 136-147 (2017).

36. Nadizadeh, A. and Kafash, B. "Fuzzy capacitated location-routing problem with simultaneous pickup and delivery demands", Transportation Letters, 11(1), pp. 1-19 (2019).

37. Lu, D. and Gzara, F. "The robust vehicle routing problem with time windows: Solution by branch and price and cut", European Journal of Operational Research, 275(3), pp. 925-938 (2019). 
38. Hu, C., Lu, J., and Zhang, G. "Robust vehicle routing problem with hard time windows under demand and travel time uncertainty", Computers \& Operations Research, 94, pp. 139-153 (2018).

39. Veysmoradia, D., Vahdani, B., Farhadi Sartangi, M., and Mousavi, S.M. "Multi-objective open locationrouting model for relief distribution networks with split delivery and multi-mode transportation under uncertainty", Scientia Iranica, 25(6), pp. 3635-3653 (2018).

40. Yu, C.-S. and Li, H.-L. "A robust optimization model for stochastic logistic problems", International Journal of Production Economics, 64(1-3), pp. 385-397 (2000).

41. Leung, S.C.H, Tsang, S.O.S., Ng, W.L., and WU, Y. "A robust optimization model for multi-site production planning problem in an uncertain environment", European Journal of Operational Research, 181(1), pp. 224-238 (2007).

\section{Biographies}

Roghayeh Vakili received her BSc degree from Amirkabir University of Tehran and MSc degree from Kharazmi University of Tehran. Her main research interests include robust optimization under uncertainty and applied operations research.

Mohsen Akbarpour Shirazi received his PhD degree in Industrial Engineering, from Amirkabir University of Technology, Tehran, Iran, where he is now an Assistant Professor. His areas of research include supply chain planning, transportation, and modeling. $\mathrm{He}$ is the author and co-author of many technical papers in these fields.

Hossein Gitinavard is currently a PhD Candidate at the Department of Industrial Engineering and Management Systems, Amirkabir University of Technology, Tehran, Iran. He received BSc and MSc degrees from the School of Industrial Engineering, University of Tehran and School of Industrial Engineering, Iran University of Science and Technology, respectively. His main research interests include fuzzy sets theory, multicriteria decision-making under uncertainty, artificial neural networks, and applied operations research. He has published several papers in reputable journals and international conference proceedings. 